\title{
Diclofenac Induced Urticarial Angioedema : A Case Report
}

\author{
Dr.Mary Rohini.P ${ }^{1}$,Dr.Shashidhar Reddy ${ }^{2}$,Dr.Prasanna.V $V^{3}$, \\ Dr.Sangeeth Kumar.K ${ }^{4}$,Dr.Jagadish.L ${ }^{5}$. \\ ${ }^{1}$ Dept of Pharmacology, RVMIMS \& RC, Laxmakkapally, telangana,india \\ ${ }^{2}$ Dept of General medicine, RVMIMS\&RC, laxmakkapally, telangana, india \\ ${ }^{3}$ Dept of Pharmacology, RVMIMS \& RC, Laxmakkapally, india. \\ ${ }^{4}$ Dept of Dermatology, RVMIMS \& RC, Laxmakkapally, india. \\ ${ }^{5}$ Dept of Pharmacology, RVMIMS \& RC, Laxmakkapally, india.
}

\begin{abstract}
NSAIDs are the most commonly used drugs in the treatment of pain of different types. Aspirin, Ibuprofen and diclofenac are the most common NSAIDS associated with angioedema. Angioedema is a rare adverse effect occurring with an incidence of 0.1 to $0.3 \%{ }^{1}$ and incidence increases with age. Early recognition and discontinuation of the drug is important. Anti-histamines and corticosteroids are used in the management of urticarial angioedema.
\end{abstract}

Keywords: Diclofenac, NSAIDS, Angioedema.

\section{Introduction}

NSAIDs are the most commonly used drugs in the treatment of pain of different types. These drugs are well tolerated with few side effects. Angioedema is a rare adverse effect occurring with an incidence of 0.1 to $0.3 \%$. coexistance of urticaria with angioedema is uncommon. Aspirin, Ibuprofen and diclofenac are the most common NSAIDS drugs associated with angioedema.Andioedema is an abrupt swelling of the skin, mucous membranes of the face, lips, mouth, larynx, extremities and genitalia ${ }^{2}$. The most common cause of angioedema is allergic angioedema, common site is lips and around the eyes. Allergic angioedema is a hypersensitivity reaction to various causes such as drugs, foods, insect stings ${ }^{1}$. We report a case of diclofenac induced urticarial angioedema.

\section{Case Report}

A 56 years old lady who underwent Percutaneous Nephrolithotomy and DJ stent placement for renal calculi presented with complaints of diffuse abdominal pain to the casuality for which injection diclofenac 2c.c intramuscular was administered. Twenty minutes after the administration of injection diclofenac sodium, she developed severe itching over the cheeks, periorbital region and over the neck. This was followed by rash, redness and urticaria all over the face, over the lateral side of neck (as shown in fig 1 and fig 2) and all over the body. After one day she also developed swelling of the lips. She did not give any history of allergy to medication nor history of similar complaints in the past. Physical examination was normal except for erythema and multiple annular wheals all over the body including face and swelling of the lips. She was treated with injection Chlopheniramine maleate 2c.c and injection hydrocortisone $100 \mathrm{mg}$ IV immediately followed by injection dexamethasone 2c.c and injection rantac 50mg both given intravenously, twice daily. Rash, urticaria and swelling reduced after 5 days of treatment. Her laboratory investigations at the time of admission were Neutrophillic Leucocytosis with Eosinophilia.

(WBC-16000, Neutrophils -75\%,(normal 30-70\%), Eosinphils -08\%(normal 1-6\%), Absolute eosinophil count(AEC)-1280 cells/cu mm(normal 40-400 cells/cu mm), ESR-81/mm/1 ${ }^{\text {St }}$ hour. Other laboratory investigations were normal.She was discharged after one week on complete recovery.

The causality assessment using Naranjo's ADR probability scale indicated this ADR as "Possible". 
Figure: 1

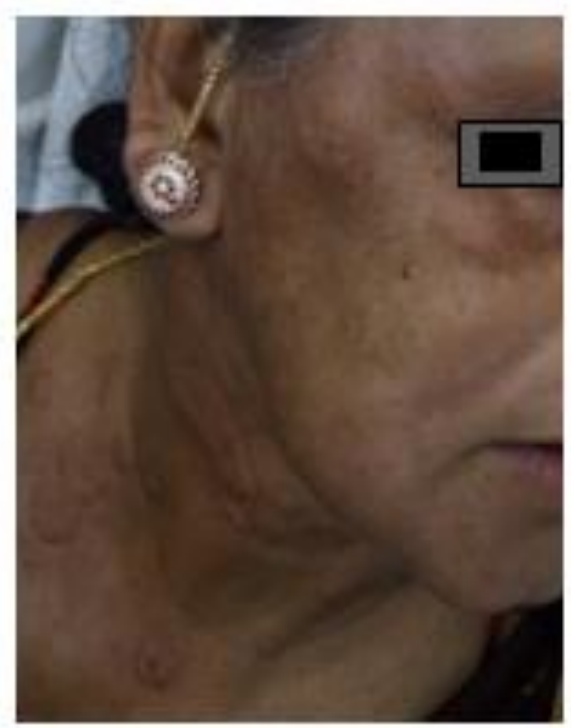

Figure: 2

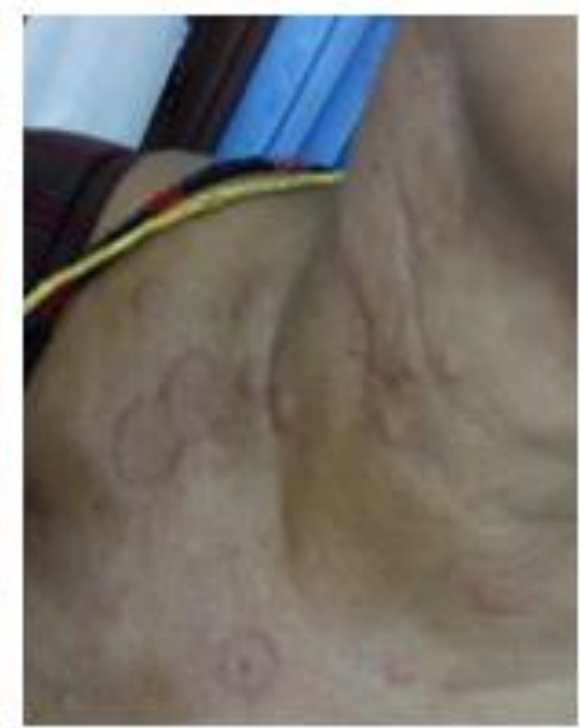

\section{Discussion}

Angioedema is known side effect of non-steroidal anti-inflammatory drugs. It is generally self limiting but may sometimes result in respiratory tract obstruction, which can prove fatal. Less severe reactions subside with medical treatment but severe reactions may require tracheostomy (or) intubation ${ }^{3}$. Diclofenac induced angioedema may be caused due to blockade of cyclooxygenase pathway which results in increased production of leukotrienes.urticaria with angioedema has been reported rarely. Early recognition and discontinuation of responsible drugs remains the main stay of treatment in NSAIDS induced urticarial angioedema. Deepa et $\mathrm{al}^{4}$ reported a similar case of urticarial angioedema in a13 year old boy, which was treated with corticosteroids and antihistamines.

In a case report by Hedar A etal. in 2010, a 39 years old women, developed angioedema and profound hemodynamic shock after receiving a diclofenac suppository for analgesia 6 hours after cesarean section ${ }^{5}$.

In another case report by Tiwari AK etal. in 2013, patient who was injected with diclofenac sodium $50 \mathrm{mg}$ intramuscular, developed chest pain and pruritis over the lip with redness and wheal over the site of injection. ECG showed ST-segment elevation in leads II, III and AVF, diagnosed as ST segment elevation myocardial infarction of inferior wall. This is referred to as Kounis syndrome, which was characterized by chest pain and allergic reaction. This can be substantiated by clinical and laboratory findings of classic angina pectoris including release of inflammatory mediators ${ }^{6}$..

\section{Conclusion}

NSAIDS and Antimicrobial agents are two major group of drugs involved in the causation of angioedema ${ }^{7}$ and urticarial rash. Generally angioedema is self limiting but sometimes can be fatal. So early recognition and discontinuation of the responsible drug is important. Usually treatment includes corticosteroids and anti-histamines. Physicians should be aware of the possibility of angioedema with urticaria while prescribing NSAIDS.

\section{References}

[1]. Konokvalai Kulthanan et al. Angioedema:clinical and etiological Aspects: Clinical and Developmental Immunology doi:10.1155/2007/26438.

[2]. Kaplan AP,Greaves MW.” Angioedema",Journal of the American Academy Of Dermatology.2005;53[3\}:373-388.

[3]. Arnon B. Angioedema-Induced by angiotensin converting enzyme inhibitors. J Clin Case Rep 2012;2(10):153.

[4]. Deepalatha c,raja vikram prasad, satish chandra,p. murali mohan, vijaya lakshmi, Diclofenac-induced urticaria in paediatric patient,,asian journal of pharmaceutical and clinical research. vol 6, suppl 3, 2013 issn - 0974-2441.

[5]. Hedar A, Holcberg G, Mazor M. Anaphylactic shock after diclofenac sodium (volteran). Harefuah ., 2000; 138(3): 211-12

[6]. Tiwari AK, Tomar GS,Kapoor MC.Kouis syndrome resulting from anaphylaxis to diclofenac. Indian J Anaesth., 2013; 57(3): 28284.

[7]. Pise HN, Padwal SL. Diclofenac induced angioedema: A Case Report. Asian J Of Pharm Clin Res.,2015; 8(2):4-5. 